\title{
Some Late Byzantine Papyri from Hermopolis
}

$\mathbf{I}^{\mathrm{N}}$ this contribution I publish five papyri from the collection in the British Library (London) which drew my attention because of their dating formula $\left({ }^{1}\right)$.

1. P. Lond. III 867 descr. (cf. plate 81 )

This Hermopolitan contract from A.D. 506 was only described in P. Lond. III, p. xli. A plate, however, was given in P. Lond. III, Plates \# 81. This plate shows that at the time of its printing the top fragment of the papyrus was mounted incorrectly. The papyrus is broken along various folds and when the fragments were put next to each other, a fragment was misplaced. The plate shows the fragments in the order (lines 1-7):

but one should read them in the order

We are dealing with some kind of contract between a woman and a soldier Fl. Danielius. The latter has occurred already before in PSI IV 292.2 (A.D. 520) and possibly also in P. Lond. III 994 (p. 259).15. He belonged to a well-known army unit, viz. the Mauri (for literature cf. $P$. Charite 7.3-5n.). The exact nature of the contract escapes us, as we have not found suitable parallels to restore lines 8-14. So much seems certain, that a sale of 2 arouras (cf. line 9), a worker in a vineyard (cf.

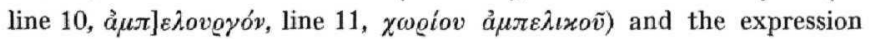
of a willingness to pay something mentioned earlier in the lost part of

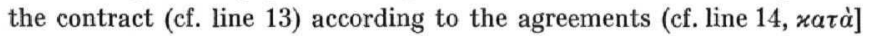
$\tau \dot{\alpha}$ бú $\mu \varphi(\omega v \alpha)$ were involved.

(1) I should like to thank Dr. T. S. Pattie for his kind permission to publish these texts. Likewise, I should like to thank Dr. R. W. Daniel (Leiden) who kindly revised my English and discussed some problems of reading and interpretation connected with these papyri. 
Hermopolis

20.iii.506

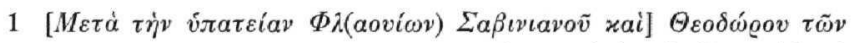
$\lambda \alpha \mu \pi \varrho \circ(\tau \alpha \dot{\tau} \omega \nu) \Phi \alpha \mu \varepsilon \nu \dot{\omega} \theta x \delta$

$2[\quad \tau \tilde{\eta} \varsigma \tau \varepsilon \sigma \sigma \alpha \varrho \varepsilon \sigma \varkappa \alpha \iota \delta \varepsilon x a ́ \tau \eta \varsigma ~ i v] \delta(\iota x \tau i \omega \nu о \varsigma)$

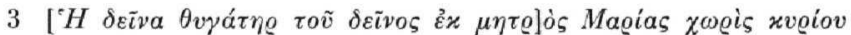
àvঠò̀s

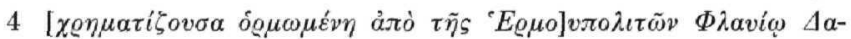

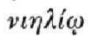

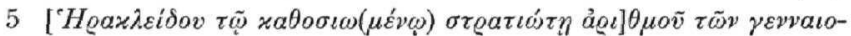

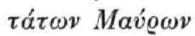

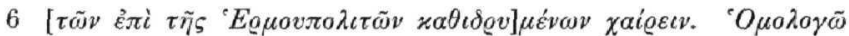

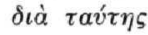

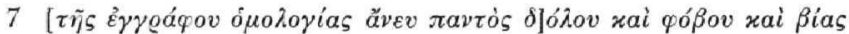

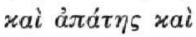

8

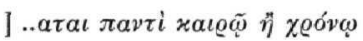
] $\sigma \tau \iota v \tau \dot{\nu} v \pi \varrho \tilde{\alpha} \sigma \iota v \tau \tilde{\omega} v \delta \dot{v} o \alpha ̉ \varrho o v \varrho \tilde{\omega} v$

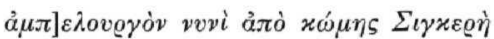

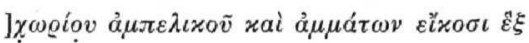

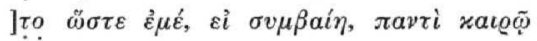

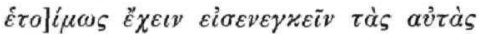

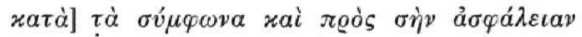

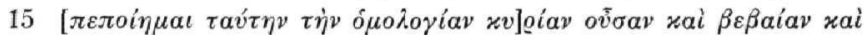

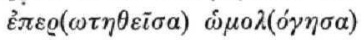

16 [(M. 2) ${ }^{\circ} H \delta \varepsilon i v \alpha$

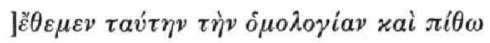

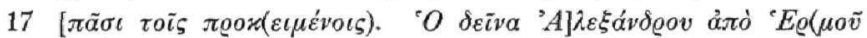

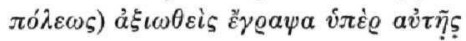

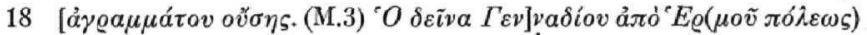

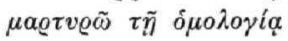

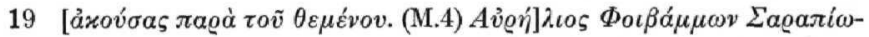

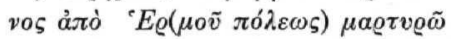

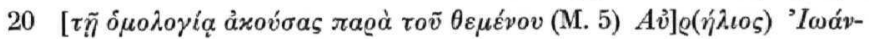

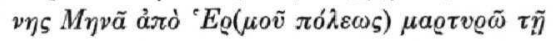
$14 \pi \varrho o ́ \zeta: \pi$ ex $\varepsilon$ corr. 16 read $\varepsilon \dot{\theta} \varepsilon \dot{\mu} \mu \eta$ and $\pi \varepsilon i \theta \omega \quad 17$ ï $\pi \varepsilon \varrho$ 


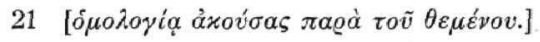

22 [ (M.6)

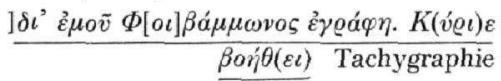

1. For the (post-)consulate of Sabinianus and Theodorus cf. R. S. Bagnall - K. A. Worp, Chronalagical Systems of Byzantine Egypt, 121, years 505-506. The restoration of a post-consular formula is warranted in view of the length of the restorations (ca. 30 letters) elsewhere in this text.

2. Apparently, this line was indented, even with the restoration of the indiction numeral written out in full. An insertion of something like $\varepsilon v ่ \tau v \chi o \tilde{v} \varsigma$ or $\pi a \varrho o v ́ \sigma \eta \zeta$ after $\tau \tilde{\eta} \varsigma$ would seem out of place in a dating formula at the start of a document.

3. For the women $\chi \omega \varrho i \varsigma$ xvoíov $\chi \varrho \eta \mu \alpha \tau i \zeta o v \sigma \alpha \iota$ cf. the list in $P$. Mich. XV, pp. 158-171, esp. \$102 where this papyrus is listed. The text does not mention a $\sigma v v \varepsilon \sigma \tau \omega ́ \varsigma$ (the element $\alpha \dot{\nu} \delta \varrho o ́ \varsigma$ should be shifted from col. VII to col. V).

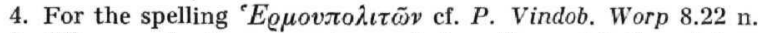

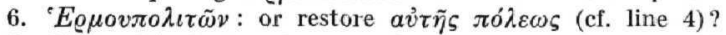

7. Cf. for this cluster of more or less synonymous concepts Preis. WB, s.v. $\beta i \alpha, 7$, and H. Zilliacus, Zur Abundanz der spätgriechischen Gebrauchssprache, 51.

10. For the village called Sinkere cf. M. Drew-BEAR, Le Nome Hermopolite, 254-56.

11. For the size of ammata (normally $1 / 64$ of an arura) cf. P. Bad. IV $92.4 \mathrm{n}$.

14. Presumably the scribe started to write $\varepsilon i \varsigma$, then corrected this into

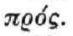

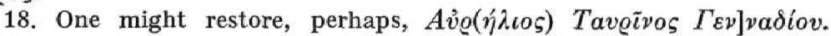
This person occurs as a hypographeus in P. L. Bat. XIII 16.19 (for this papyrus see below, 22n.). On the other hand, however, one finds a Basilides, son of Gennadius, in BGU XII 2152.2, 14 (Vth century).

20. This witness also occurs in $P S I$ IV 296.27, where one should pre-

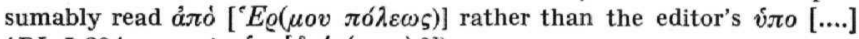

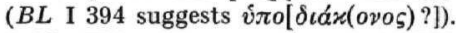

22. This same notary occurs in P.L.Bat XIII 16.23 (cf. Taf. VII; ed. VI-VII, but one should rather date this papyrus to V-VI). The notary Phoibammon out of CPR VII 40.32 (492; cf. Taf. 28) does not seem to be the same notary as his subscription is written differently. Other late V/ early VI notaries called Phoibammon in Hermopolis are found in $B G U$ XII 2149 (470), 2159 (485) and 2175 (V/VI).

For the element $x(v ́ \varrho \iota) \varepsilon \beta o \eta ́ \theta(\varepsilon \iota)$ cf. J. M. Diethart in $Z P E 49$ (1982) 79-82 where 5 instances of it given in papyri published to date are mentioned. To these may be added P. Stras. 247.25, where read $\delta \iota^{\prime} \dot{\varepsilon} \mu o \tilde{v}$ ' $A \pi o \lambda$ -

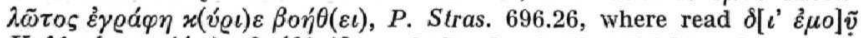

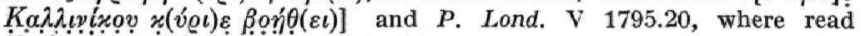
$\dot{\delta}\left[\iota^{\prime} \bar{\varepsilon}\right] \mu \sigma \tilde{v}-[\dot{\varepsilon} \gamma] \underline{g} \alpha \dot{\varphi}(\eta) \psi(\hat{v} \varrho \iota) \varepsilon \beta a \eta^{\prime} \theta(\varepsilon c)$ [the notary's name cannot be read]. 
This start of a lease is dated by the regnal dating formula commonly in use in Hermopolitan documents under the emperor Justinus II ; cf. R. S. Bagnall-K. A. Worp, Regnal Formulas in Byzantine Egypt, 50 form. 3. Given the fragmentary state of the papyrus we cannot establish the object of the lease.

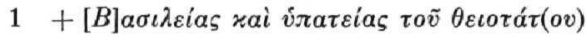

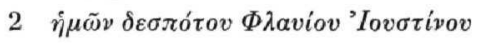

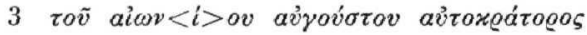

$$
\begin{aligned}
& 4 \text { Eั่ }
\end{aligned}
$$

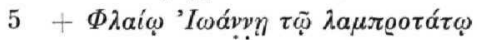

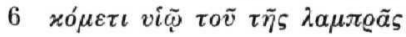

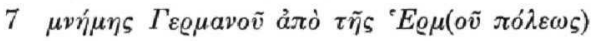

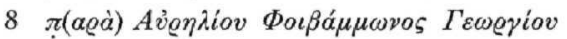

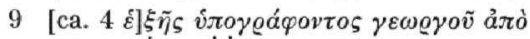

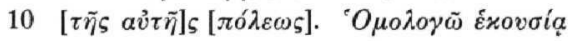

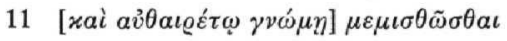

$$
\begin{aligned}
& 12 \text { [ ] Traces }
\end{aligned}
$$

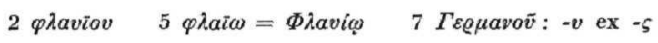

\section{Notes :}

5. I have not found other attestations of the comes Flavius Johannes among papyri jrom Hermopolis. Cf. J. G. KeEnaN in ZPE 11 (1973) 57 n. 106 for comites with the name Flavius.

9. It is unclear to me what could have stood in the lacuna at the start of this line. There seems hardly space enough for $\mu \eta(\tau \varrho o$ s) followed by a name, but as we do have already the patronymic and the profession of Aurelius Phoebammon, there are not many other alternatives for a restoration of his mother's name. Dr. Daniel suggests to restore just

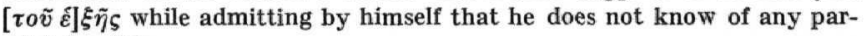
allel for this. 
3. P. Lond. III $1326 b$ descr. (cf. plate 91)

For this start of a lease of a vine-yard cf. already the discussion of the dating formula in BASP 16 (1979) 244-245. The document does not present further novelties of its own, except for possibly a new geographical name in line 7 (see note).

Hermopolis

26.iv.583

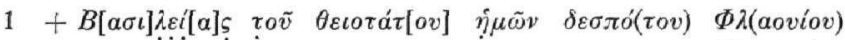
Maveıxiov

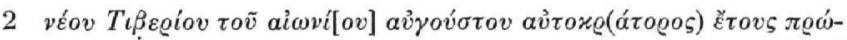

3 Пах

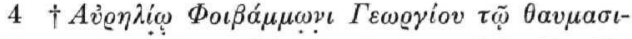

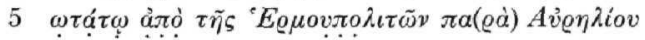

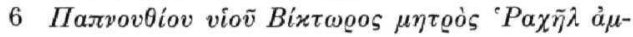

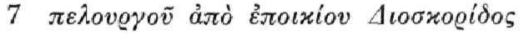

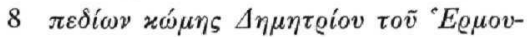

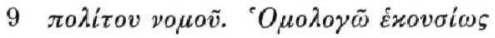

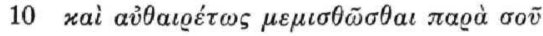

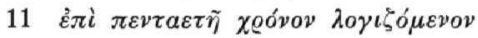

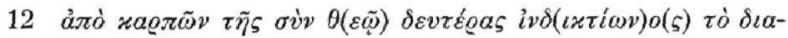

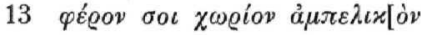

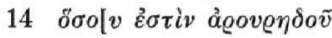

$12 \tau \nu \delta$

\section{Notes :}

5. $\pi \alpha(\varrho \alpha ́)$ was abbreviated by a diagonal stroke written throngh a pi with an alpha on top of it.

7. An epoikion (?) Dioskorou is known from P. Cair. Preis. 30.19 ; maybe we are dealing with the same village under a slightly variant name.

8. For the village of Demetrius see M. DREw-BEAR, Le nome Hermopolite, 90 .

14. For this clause ef. H. JuLY, Die Klauseln hinter den Massangaben der Papyrusurkunden, 42. 


\section{P. Lond. III 1315a descr.}

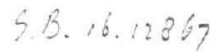

This badly mutilated papyrus contains a fragment of a lease. It is dated to the reign of the emperor Mauricius (A.D. 582-602), but the regnal year itself is lost. As the top of the papyrus is completely preserved (thus no invocation seems to have broken off), the date of the papyrus most likely falls before A.D. 591 (cf. CdE 56 [1981] 112 ff., esp. 117). Indiction 3 (line 3 ) $=$ A.D. $584 / 5$, then, and Mesore $20=13$.viii. As the document comes from Hermopolis, this combination of dating elements leads to a date to 13.viii.584 in our calendar, but we cannot say whether the scribe dated his document to Mauricius' 2nd or to his 3rd regnal year, as 13.viii itself was the dies imperii of Mauricius (cf. R. S. Bagnall - K. A. Worp, Regnal Formulas in Byzantine Egypt, 58) and as the scibe may have failed to advance the regnal numeral on this very day (cf. BASP 17 [1980] 62 ff.).

The precise object of the lease is not known. In line 11 we encounter a numeral 55 which might be taken as an indication of the number of

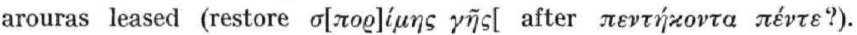
A plot of land of 55 arouras would be rather large, however. A consultation of the tables in D. Hennig, Untersuchungen zur Bodenpacht im ptolemäisch-römischen Agypten (Diss. München, 1967), yields the impression that in later Byzantine Egypte the number of arouras leased was mostly lower than 10 (the number of 200 ar. in P. Ross. Georg. III 32 [cf. A. Ch. Johnson - L. C. West, Byzantine Egypt, 84] is astonishingly high and may be the result of some mistaken reading).

HERMOPOLIS

13.viii.584

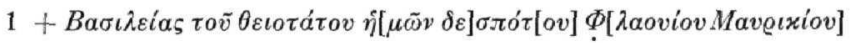

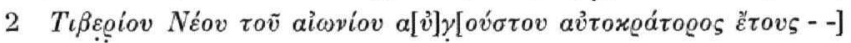

3 [iv]

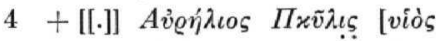

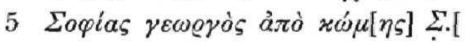

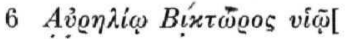
$\mu \eta \tau \varrho o ̀ s]$

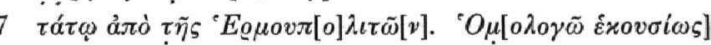

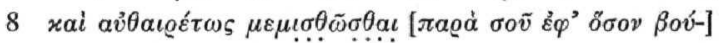

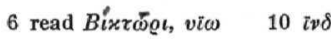




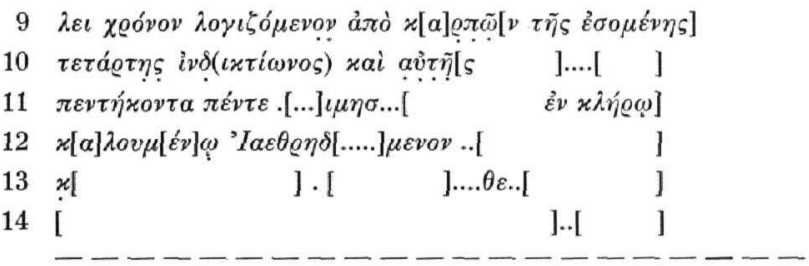

\section{Notes :}

1-3. The formula is $R F B E 61$, form. 7 ; this reference has to be added there, of course. One may reckon with abbreviations like $\Phi \lambda$ (aoviov),

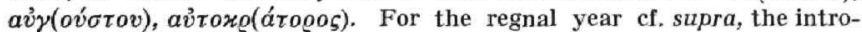
duction.

It is remarkable that the indiction precedes the month and that, moreover, this is in the dative, the day of the month in the nominative. Normally the month and day (in the dative) precede the indiction (in the genitive). For another example of a day of the month in the nominative

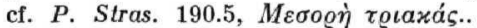

5. It is also possible that one should read $\varkappa \omega \mu[\eta] \varsigma$. $[-$.

6-7. For epithets which could suitably be restored cf. J. Herrmann, Studien zur Bodenpacht, 48-49.

7. It is also possible to read and restore 'E ${ }^{\circ} \mu o v \pi[0] \lambda \iota \tau \tilde{\omega}[\nu \pi]$ ó $\lambda \varepsilon[\omega \zeta$.

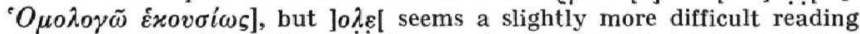

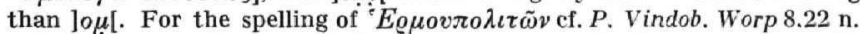

7-10 For the phrasings used in this passage ef. J. Herrmann, op. cit., $50,92-98$. The coming 4 th indiction was A.D. $585 / 6$, the crops of which were harvested in the summer of A.D. 585.

10-12. One expects here a description of the localization of the lease object (cf. J. Herrmann, op. cit., 76-77). For the kind of lease object see supra, the introduction. One might consider a reading $\varkappa[a] \lambda o v \mu[\varepsilon ́ v \omega]$

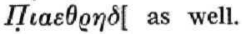

\section{P. Lond. III 1304a descr.}

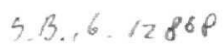

We are dealing, apparently, with a contract in which a person assumes the obligation to perform work for a period of 1 year as a bath-man in the service of a private owner of a bath. The terminology used in the contract is slightly remarkable in that the kind of service is called on the

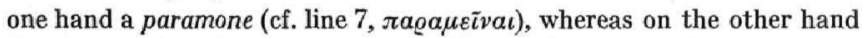
the contract itself is called a misthotike homologia (line 6). It is, however, well-known that in Byzantine papyri the original distinction between 
paramone and misthosis is maintained no longer in a clear way (cf. B. Adams, Paramone und Verwandte Texte, 25). For baths in the Byzantine period cf. A. Berger, Das Bad in der Byzantinischen Zeit; (= Miscellanea Byzantina Monacensia 27, München, 1982), who does not discuss, however, the evidence concerning baths in Byzantine Egypt except for Alexandria. It should be noted that the restorations proposed for the lacunas in lines $6 \mathrm{ff}$. are just exempli gratia and that they might be too short in fact. If so, one might pad them with the help of various peri-

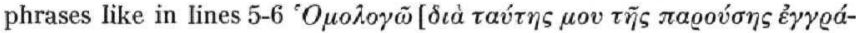

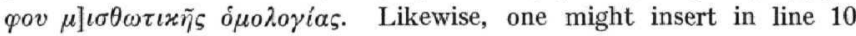

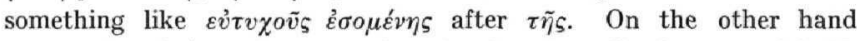

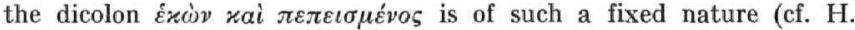
Zilliacus, Zur Abundanz der spätgriechischen Gebrauchssprache, esp. 49), that one cannot insert something in between and that it is not easy to devise some other supplement which should follow after these words while suitably filling the remaining space (the phrasing in $P$. Lond.

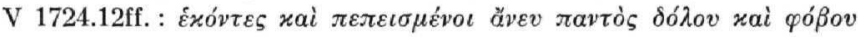

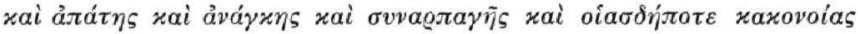

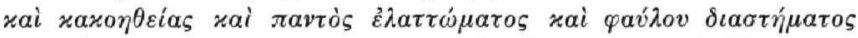

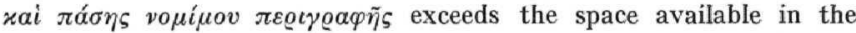
lacuna here). On the other hand the restoration found now at the start of lines 1-2 can be made shorter by assuming that there was an extensive use of abbreviations and nomina sacra in the parts lost. For the general contents of the contract, however, this is hardly of any importance.

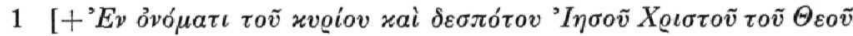

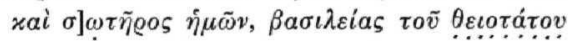

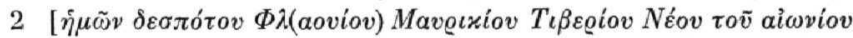

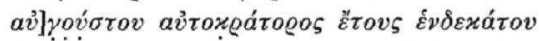

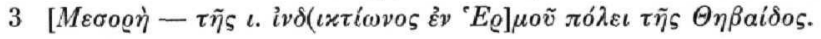

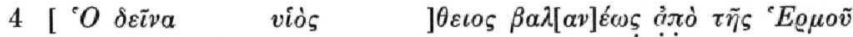

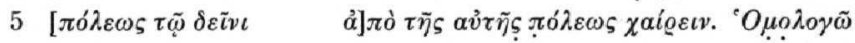

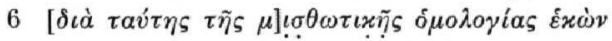

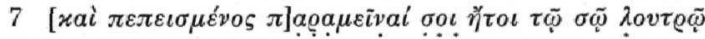

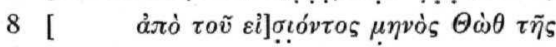

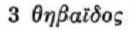
4 read Baiavev́s

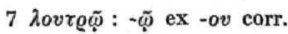




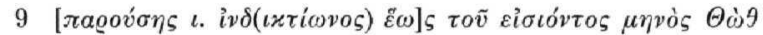

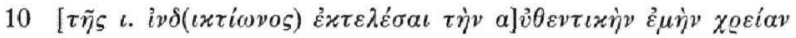

11 [ ].....]...[.]..[.]. $\varepsilon \lambda \varepsilon \omega[.] \gamma \varepsilon v \alpha \mu[$ ]

12 [ ] $\theta \varepsilon \iota \omega \nu \delta \varepsilon \chi[$ ] Traces

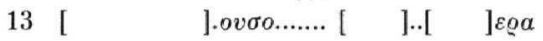

14 [ ]Traces [ ] Traces

\section{Notes :}

1. For the invocation see $C d E 56$ (1981) $112-33$. For the regnal formula cf. RFBE 61, form. 7 .

4. It seems likely that $] \theta \varepsilon i o \zeta$ is the ending of a patronymic and that the writer erroneously wrote $\beta \alpha \lambda a v \varepsilon \varepsilon_{\zeta}$ instead of $\beta a \lambda a v \varepsilon v ́ s$. In the context of the contract it is not so much important to indicate that the father of the contractor was a bath-man as it was to indicate that the contractor himself was. For the function of a $\beta a \lambda \alpha v e v$ s ef. A. BERGER, op. cit., 122.

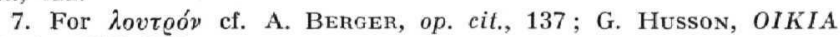
(Paris, 1983) 157f.

8. One expects at the start of this line either an indication of the place where the bath was situated, or an indication of the period of time for

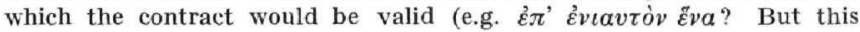
supplement would be rather long in view of the space available).

10. Instead of $\dot{\varepsilon} x \tau \varepsilon \hat{\lambda} \varepsilon \sigma \alpha \iota$ one could also restore e.g. $\alpha \dot{\pi} \sigma \pi \lambda \eta \varrho \tilde{\omega} \sigma \alpha \iota$ 11-14. The remains of these lines are too scanty to be safely restored with the help of parallel documents.

The regnal year of this contract was already discussed in BASP 17 (1980) 109-10 where it was concluded that the document can have been written only during the reign of the emperor Mauricius. His 11th year ran from 13.viii.592 until 12.viii.593. Line 8 tells us that the contract would be effective per the coming month of Thoth, and it seems likely, therefore, that the contract was drawn up in the preceding month, i.e. in Mesore (or even slightly earlier, perhaps). There is, therefore, a probIem as regards the numeral of the indiction to be restored in lines 3,9 and 10. If the contract was drawn up between Mesore $20(=13$.viii) and Mesore 30, we would be in the summer of A.D. 592 and the numeral of the indiction would be 11 in lines 3 and 9 , but it would be 12 in line 10 . But if the contract were drawn up on a date before Mesore 20, we would be in the summer of A.D. 593 and the numeral of the indiction would shift one notch.

Amsterdam

Klaas A. WorP 